\title{
Ender3 3D printer kit transformed into Open, Programmable Syringe Pump set
}

\author{
Sander Baas, Vittorio Saggiomo
}

Laboratory of BioNanoTechnology, Bornse Weilanden 9,

Wageningen University and Research, Wageningen, The Netherlands

Vittorio.saggiomo@wur.nl

Twitter: @Sander_Says, @V_Saggiomo

\section{Introduction}

Syringe pumps are an excellent tool used in many different fields: from physics [1], flow chemistry [2], microfluidics [3,4], to biology and microscopy [5]. However, even a simple syringe pump, with little possibility of automation, can cost close to $€ 1000$ [6]. Because of the high cost and the limited automation capability, many groups around the world have switched to a Do It Yourself (DIY) approach [7,8]. Many DIY pumps have been published in the last few years using stepper motors and lead screws to translate the rotational motion of the motor to linear motion of a syringe plunger. Recently the group of Pachter published a Python controllable pumps system, called Poseidon [9], where the whole pump frame is 3D printed. Some designs use ready-made parts for the frame, such as metal rods [10] or aluminum extrusions [11]. Henriques' group built a set of pumps using Lego blocks and controlled them using Arduino [12]. In general, Arduino is a popular control board for DIY syringe pump systems [6,13-15]. The Raspberry Pi single board computer is also used for pump control [16], also in combination with commercial pumps [17]. Non syringebased DIY pump designs, such as peristaltic [18-20] and manually operated pumps [21,22] have also been demonstrated.

Although all these pumps work correctly and are an excellent opportunity to enter the Open Hardware DIY instruments field, building and programming them requires, first, the sourcing of all the parts from different vendors and then, some previous knowledge in programming to use them. The sourcing of the parts may result in a scavenger hunt, with parts changing name or vendor and specs over time. Another barrier is the knowledge of electronics and programming that is usually required to build and use these pumps. These two problems may hinder the widespread adoption of DIY pumps among researchers without previous knowledge in these areas. Moreover, they may not be willing to spend time in a build process if they first must acquire these skills.

To solve the issues of acquiring many parts and going through a complicated build process, we leverage the use of a 3D printer electronics and mechanics for building and controlling a set of three syringe pumps. A standard fused deposition modelling (FDM) 3D printer has, in fact, all the components required to build a set of syringe pumps: stepper motors, motherboard, power supply (PSU), and linear motion systems in the three XYZ axes. Moreover, the program used for controlling 3D printers, usually Marlin [23] working with G-code files, can be exploited for controlling the syringe pumps. This avoids the need of programming the pumps from scratch, using microcontrollers like Arduino or the Linux based Raspberry Pi.

In this paper, we show how to build and use a set of 3D pumps by repurposing a Creality Ender3 [24], one of the cheapest FDM printers on the market. Apart from three shaft couplers, one M5 threaded rod and three M5 nuts, everything needed for this build is included in the Ender 3 box, even the screws and the tools needed for assembly. Some additional parts that are needed for the syringe and motors connections are 3D printed, meaning that the Ender 3 can be first built for 
printing the parts, and then disassembled for building the syringe pumps (Fig. 1). We also show how to use G-code for controlling and automating the pump system.

This approach of repurposing a 3D printer and control via G-code for use as syringe pumps is cheap, fast, and simple [25]. It opens the opportunity of acquiring and using syringe pumps in laboratories around the world, independent of funding and previous knowledge in programming and electronics.

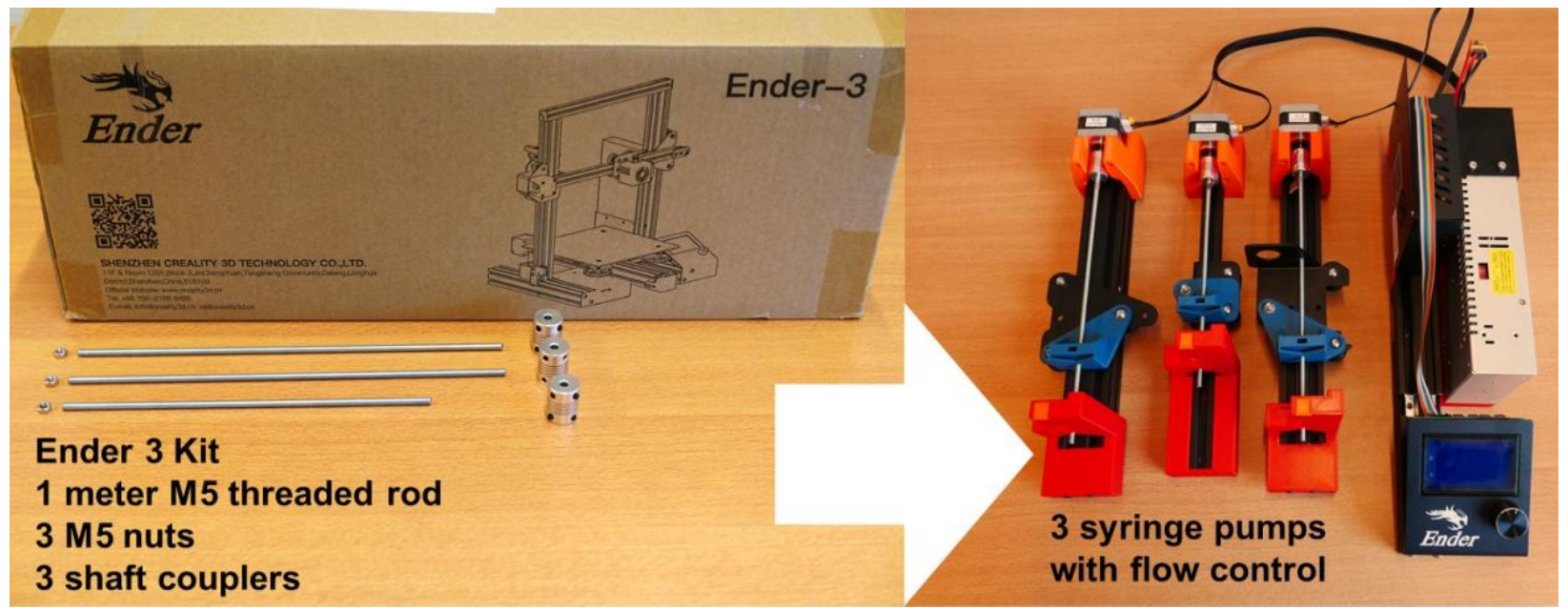

Figure 1 An Ender 3 3D printer kit can be repurposed to build a three channel syringe pump system. Additional purchased components are limited to one meter M5 threaded rod, three M5 nuts and three $5 \times 5$ shaft couplers. All custom parts can be $3 D$ printed.

\section{Hardware description.}

This project describes the procedure to repurpose a 3D Printer to a set of three syringe pumps. All the components, even the screws and the tools needed for the build are in the 3D printer box, simplifying the acquisition of each separate component. The only additional parts to be purchased are 5x5 shaft couplers, M5 nuts and M5 threaded rods, available at any hardware store. The 3D printed parts are supplied in their original CAD format (.F3D) as well as .STL files ready to be 3D printed. Printable parts were designed using Fusion 360 from Autodesk. For this specific project, we used a Creality Ender 3 3D printer, as it is one of the cheapest FDM on the market, and it is open source/open hardware [26]. However, as all FDM 3D printers work by moving a XYZ stage, this method can be applied to any 3D printer by redesigning the 3D printed parts, while the G-code programming will remain the same.

In fact, the programming of the pumps is also easy as it leverages the Marlin firmware already present on many 3D printer motherboards, and G-code files for controlling the pumps can be easily written as text files.

This project comprises of an easy to assemble and program syringe pump set, which can be used for:

- Flow chemistry

- Microfluidics

- Biology and Microscopy (for example for automatic staining and fixing)

Moreover, this project can be used as a blueprint to expand the possibilities of repurposing 3D printers for laboratory equipment. For example, in the 3D printer kit, there is a fourth motor, two 
heating units with thermistor controls and three end stops, which are not used in this project, but can be useful to build other instruments. The project files and description are available on github [27].

\section{Design files}

\section{Print settings}

All the design files listed in Table 1 were printed using PLA material, at $0.2 \mathrm{~mm}$ layer height, $20 \%$ infill, with two perimeter wall thickness. The designs are printable without using support structures.

Table 1 Design file overview, with the file name of the part, the available file types, license type and the repository location.

\begin{tabular}{|c|c|c|c|}
\hline Design file name & File type & $\begin{array}{l}\text { Open source } \\
\text { license }\end{array}$ & Location of the file \\
\hline Clamp Bar Long v1 & $\begin{array}{l}\text { F3D (Fusion } \\
\text { 360), STL }\end{array}$ & CC-BY 4.0 & $\begin{array}{l}\text { https://github.com/Vsaggiomo/Ender3- } \\
\text { syringe-pumps }\end{array}$ \\
\hline Clamp Bar Short v1 & $\begin{array}{l}\text { F3D (Fusion } \\
\text { 360), STL }\end{array}$ & CC-BY 4.0 & $\begin{array}{l}\text { https://github.com/Vsaggiomo/Ender3- } \\
\text { syringe-pumps }\end{array}$ \\
\hline Clamp Bar v1 & $\begin{array}{l}\text { F3D (Fusion } \\
\text { 360), STL }\end{array}$ & CC-BY 4.0 & $\begin{array}{l}\text { https://github.com/Vsaggiomo/Ender3- } \\
\text { syringe-pumps }\end{array}$ \\
\hline Dovetail Cap v1 & $\begin{array}{l}\text { F3D (Fusion } \\
\text { 360), STL }\end{array}$ & CC-BY 4.0 & $\begin{array}{l}\text { https://github.com/Vsaggiomo/Ender3- } \\
\text { syringe-pumps }\end{array}$ \\
\hline E End Mount v1 & $\begin{array}{l}\text { F3D (Fusion } \\
\text { 360), STL }\end{array}$ & CC-BY 4.0 & $\begin{array}{l}\text { https://github.com/Vsaggiomo/Ender3- } \\
\text { syringe-pumps }\end{array}$ \\
\hline E Slide Mount v1 & $\begin{array}{l}\text { F3D (Fusion } \\
\text { 360), STL }\end{array}$ & CC-BY 4.0 & $\begin{array}{l}\text { https://github.com/Vsaggiomo/Ender3- } \\
\text { syringe-pumps }\end{array}$ \\
\hline E Stepper Mount v1 & $\begin{array}{l}\text { F3D (Fusion } \\
\text { 360), STL }\end{array}$ & CC-BY 4.0 & $\begin{array}{l}\text { https://github.com/Vsaggiomo/Ender3- } \\
\text { syringe-pumps }\end{array}$ \\
\hline Electronics Base v1 & $\begin{array}{l}\text { F3D (Fusion } \\
\text { 360), STL }\end{array}$ & CC-BY 4.0 & $\begin{array}{l}\text { https://github.com/Vsaggiomo/Ender3- } \\
\text { syringe-pumps }\end{array}$ \\
\hline PSU Mount v1 & $\begin{array}{l}\text { F3D (Fusion } \\
\text { 360), STL }\end{array}$ & CC-BY 4.0 & $\begin{array}{l}\text { https://github.com/Vsaggiomo/Ender3- } \\
\text { syringe-pumps }\end{array}$ \\
\hline $\begin{array}{l}\text { X Motor Slide Mount } \\
\text { v1 }\end{array}$ & $\begin{array}{l}\text { F3D (Fusion } \\
\text { 360), STL }\end{array}$ & CC-BY 4.0 & $\begin{array}{l}\text { https://github.com/Vsaggiomo/Ender3- } \\
\text { syringe-pumps }\end{array}$ \\
\hline X Slide Mount v1 & $\begin{array}{l}\text { F3D (Fusion } \\
\text { 360), STL }\end{array}$ & CC-BY 4.0 & $\begin{array}{l}\text { https://github.com/Vsaggiomo/Ender3- } \\
\text { syringe-pumps }\end{array}$ \\
\hline $\begin{array}{l}\text { X X Motor End Mount } \\
\text { v1 }\end{array}$ & $\begin{array}{l}\text { F3D (Fusion } \\
\text { 360), STL }\end{array}$ & CC-BY 4.0 & $\begin{array}{l}\text { https://github.com/Vsaggiomo/Ender3- } \\
\text { syringe-pumps }\end{array}$ \\
\hline $\begin{array}{l}\text { X X Motor Stepper } \\
\text { Mount v1 }\end{array}$ & $\begin{array}{l}\text { F3D (Fusion } \\
\text { 360), STL }\end{array}$ & CC-BY 4.0 & $\begin{array}{l}\text { https://github.com/Vsaggiomo/Ender3- } \\
\text { syringe-pumps }\end{array}$ \\
\hline
\end{tabular}




\section{Clamp Bar (Long, Normal, Short)}

The Clamp Bar is used to keep the syringe pressed against the End Mount frame, under pressure of a spring. Three lengths are available, in order to accommodate different syringe diameters, if the spring pressure is insufficient, or too great.

\section{Dovetail Cap}

A cap to lock the spring and Clamp Bar in place. It slides in with a dovetail-type mechanism.

\section{E End Mount}

The mount for the E Plate Pump in which the syringe body is clamped.

\section{E Slide Mount}

The mount that is installed on the E Slide Plate, which moves the syringe plunger.

\section{E Stepper Mount}

The E Stepper Mount is used to mount the stepper motor, driving the leadscrew.

\section{Electronics Base}

A base to support the Electronics Box when it is mounted on the Control Unit.

PSU Mount

A rectangular block that connects the PSU to the Control Unit.

X Motor Slide Mount

The mount that is installed on the X Motor Slide Plate, which moves the syringe plunger.

\section{Slide Mount}

The mount that is installed on the X Slide Plate, which moves the syringe plunger.

\section{X Motor End Mount}

The mount for the X Plate and X Motor Plate in which the syringe body is clamped.

\section{X Motor Stepper Mount}

The X X Motor Stepper Mount is used to mount the stepper motor, driving the leadscrew. It is used in both the X Plate and X Motor Plate pumps. 


\section{Bill of Materials}

\begin{tabular}{|l|l|l|l|l|l|}
\hline Component & Number & $\begin{array}{l}\text { Cost per } \\
\text { unit }-€\end{array}$ & $\begin{array}{l}\text { Total } \\
\text { cost }-€\end{array}$ & $\begin{array}{l}\text { Source of } \\
\text { materials }\end{array}$ & $\begin{array}{l}\text { Material } \\
\text { type }\end{array}$ \\
\hline M5 threaded rod (1 meter) & 1 & 3.79 & 3.79 & Hardware store & Stainless steel \\
\hline M5 nut & 3 & 0.54 & $\begin{array}{l}3.59 \text { (per } \\
20)\end{array}$ & Hardware store & Stainless steel \\
\hline 5x5 shaft coupler & 3 & 3.68 & 11.04 & $123-3$ D.nl & Aluminium \\
\hline Ender 3 Kit & 1 & 140 & 140 & Aliexpress & $\begin{array}{l}\text { DIY 3D } \\
\text { printer kit }\end{array}$ \\
\hline 3D printed parts (500g) & $\begin{array}{l}1 \mathrm{~kg} \text { roll of } \\
\text { PLA } \\
\text { filament }\end{array}$ & 20 & 10 & $123-3$ D.nl & PLA \\
\hline
\end{tabular}

As stated, this project aims to enable researchers to build an Open Hardware syringe pump system, with the need for purchasing as little externally sourced components as possible. The Bill of Materials therefore consists mainly of 3D printed parts, designed to construct this pump system. The threaded rod and M5 nuts should be readily available at a hardware store. The Ender 3 can be bought online. Some online vendors specialize in the sale of 3D printers, will also sell parts like the $5 \times 5$ shaft coupler. The shaft coupler should also be available on major online stores.

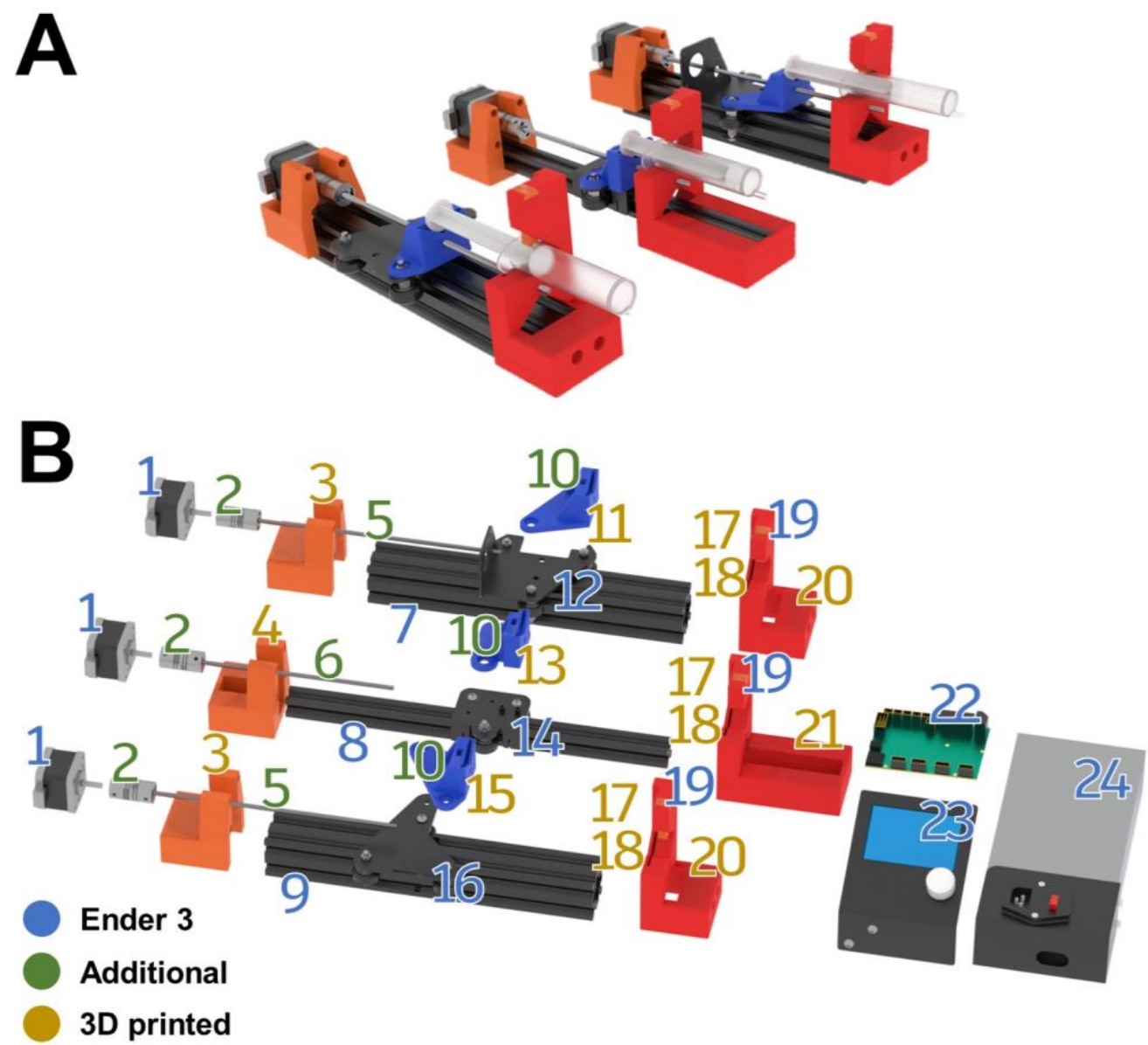

Figure 2 A) Render of the three pump channels. B) Exploded view of pump parts with number indicating the part. Blue numbers: Parts included in the Ender 3 kit. Green numbers: Additional purchased parts. Yellow numbers: $3 D$ printed designs. 
A render of the three pump channels is shown in Figure 2A. Also shown, is an exploded view of the system, with all parts numbered (Fig. 2B). An overview of these parts can be found in Table 2 , below. This gives the builder a general indication of which parts are used and where. A detailed account of the construction process can be found in the build instructions in the next section.

Table 2 Overview of the parts in the exploded view (Fig. 2B). 3D printed parts, commercially bought parts and (sub)assemblies from the Ender 3 are included.

\begin{tabular}{|l|l|}
\hline Number & Part \\
\hline 1 & Stepper Motor \\
\hline 2 & $5 \times 5$ Shaft Coupler \\
\hline 3 & X X Motor Stepper Mount \\
\hline 4 & E Stepper Mount \\
\hline 5 & 27 cm M5 leadscrew \\
\hline 6 & $22 \mathrm{~cm}$ M5 leadscrew \\
\hline 7 & $40 \times 40$ rail \\
\hline 8 & $20 \times 20$ rail \\
\hline 9 & $40 \times 40$ rail \\
\hline 10 & M5 nut \\
\hline 11 & X X Motor Slide Mount \\
\hline 12 & X Motor Plate \\
\hline 13 & E Slide Mount \\
\hline 14 & E Plate \\
\hline 15 & X Slide Mount \\
\hline 16 & X Plate \\
\hline 17 & Dovetail Cap \\
\hline 18 & Clamp Bar \\
\hline 19 & Spring \\
\hline 20 & X X Motor End Mount \\
\hline 21 & E End Mount \\
\hline 22 & Control Board \\
\hline 23 & LCD Screen \\
\hline 24 & PSU \\
\hline
\end{tabular}

\section{Build Instructions}

A detailed step by step assembly guide is provided in the supplementary information. 


\section{Operation Instructions}

The syringe pumps are controlled by the 3D printer motherboard, which is already flashed with Marlin software and therefore works with G-code. There are two ways of controlling the pumps: a) using a computer connected to the board via USB and using direct control software such as PronterFace [28] or Octoprint [29], with the latter able to be used remotely via network. B) writing the G-code file, uploading it on a microSD card and using the printer interface for printing the file without the need of a computer attached to the pumps.

A G-code file is a set of instruction which Marlin interprets line by line and passes the operations to the motors. The file is a simple text file saved as .gcode. For controlling the pumps, a few Gcode commands are needed:

M92 $\mathrm{X}<$ Steps per $\mathrm{mm}>\mathrm{Y}<$ Steps per $\mathrm{mm}>\mathrm{Z}<$ Steps per $\mathrm{mm}>$

M92 should be at the start of the G-code, as this command will set the number of steps required for moving one axis one millimeter, which in the case of the Ender 3 motors/drivers and the M5x0.8 mm threaded rod is 4000 steps per mm. The Ender 3 uses stepper motors with a step angle of $1.8^{\circ}$, or 200 steps per revolution. The TSMC2208 stepper drivers are set to 1/16 microsteps, which is the default setting for the Ender 3 . The pitch of the leadscrew is $0.8 \mathrm{~mm}$. This gives the value of 4000 steps per mm. However, as we are dealing with flows, we found that it is more userfriendly to change this command from steps per $\mathrm{mm}$ to steps per $\mathrm{mL}$. This can be easily done by calculating the distance required to push a volume of $1 \mathrm{~mL}$ depending on the diameter of the syringe used. To do this, the inner diameter (I.D.) of the syringe needs to be determined. Next, the area of the plunger can be calculated. The linear syringe travel to deposit $1 \mathrm{~mL}$ can be calculated by dividing $1 \mathrm{~cm}^{3}$ by the plunger area $\left(\mathrm{cm}^{2}\right)$. Divide this number by the steps per mm value (4000) to get the steps per $\mathrm{mL}$. We have attached a simple calculator in the supplementary material to calculate the steps per $\mathrm{mL}$ using the diameter of a syringe as input. As an example, a $10 \mathrm{~mL}$ syringe has a diameter of $15.6 \mathrm{~mm}$ and the calculated steps required to move $1 \mathrm{~mL}$ are 20927 , a $5 \mathrm{~mL}$ syringe has a diameter of $12.3 \mathrm{~mm}$ and the calculated steps are 33663. Another thing to take note of, is that in the normal configuration, the $\mathrm{X}$ and $\mathrm{Y}$ motors are inverted, so this should also be set in the M92 command by giving negative step/mm values. A M92 set up using two $5 \mathrm{~mL}$ syringes on the $\mathrm{X}$ and $\mathrm{Z}$ axes and a $10 \mathrm{~mL}$ syringe on the $\mathrm{Y}$ is therefore:

M92 X-33663 Y-20927 Z33663

This will set the number of steps per $\mathrm{mL}$ in such a way that the rest of the G-code will use this to calculate the pump movements.

\section{M302 S0}

This command will set the printer to move the motors without checking the temperature of the hot end. This is usually a 3D printer safety check for avoiding extruding material when there are some problems with the hot end. In this case the hot end is detached, so there is no risk of thermal runaway.

\section{M211 S0}

This command will disable the endstops which may cause problems as they are not connected. 


\section{G91}

Use relative positioning. This is important when multiple movements are used, otherwise the motors will start from a 0.0 .0 position and use that as reference point.

\section{G4 S<time in seconds>}

Pause the commands for a set amount of time.

\section{G1 $\mathrm{X}<\mathrm{mL}>\mathrm{Y}<\mathrm{mL}>\mathrm{Z}<\mathrm{mL}>\mathrm{F}<\mathrm{mL} / \mathrm{min}>$}

This is the command to move the syringe pumps at certain flowrates. As we set up the steps $/ \mathrm{mL}$ in the M92 command, now all the G1 codes are in $\mathrm{mL} / \mathrm{min}$. This can be a positive number or a negative number, positive for pushing and negative for retracting.

For example:

G1 X0.5 F1

Will use syringe pump $\mathrm{X}$ and will deliver $0.5 \mathrm{~mL}$ of liquid at a speed of $1 \mathrm{~mL}$ per minute.

Multiple syringes can be used at the same time:

G1 X0.5 Y0.5 Z0.5 F1

Will deliver, at the same time, $0.5 \mathrm{~mL}$ of liquid from the pumps on $\mathrm{X}, \mathrm{Y}$, and $\mathrm{Z}$ at a speed of 1 $\mathrm{mL} / \mathrm{min}$

For using different flow speed for different pumps, the total amount of liquid should be calculated taking in account that all the pumps will reach the end at the same time. For example:

G1 X2 Y1 Z2 F1

Will deliver the set amount of liquid at different flow speed, using $1 \mathrm{ml} / \mathrm{min}$ on $\mathrm{Y}$, and $2 \mathrm{~mL} / \mathrm{min}$ on $\mathrm{X}$ and $\mathrm{Z}$.

For commenting on G-code files the ";" character should be used. This can be useful in commenting the G-code with metadata.

An example of full G-code (VideoS1):

; Experiment 01 20/05/2021

; $10 \mathrm{~mL}$ syringes on the three pumps

M92 X-20927 Y-20927 Z20927 ; set the proper steps/mL for the 10mL syringe

M302 S0 ; print without checking temperature

$\mathrm{G} 91$; relative positioning

; deliver $1 \mathrm{~mL}$ at $2 \mathrm{~mL} / \mathrm{min}$ sequentially

G1 X1 F2

G1 Y1 F2

G1 Z1 F2

; wait for 10 seconds

G4 S10

; deliver $1 \mathrm{~mL}$ on $X$ and $Z$ at $1 \mathrm{~mL} / \mathrm{min}, 2 \mathrm{~mL}$ on $Y$ at $2 \mathrm{~mL} / \mathrm{min}$

G1 X1 Y2 Z1 F1

; wait 10 seconds

G4 S10

; deliver $1 \mathrm{~mL}$ at $2 \mathrm{~mL} / \mathrm{min}$ sequentially

G1 Z1 F2

G1 Y1 F2

G1 X1 F2

Without previous knowledge in programming and in a few lines of G-code it is possible to program the syringe pumps to do multiple operations. This file can now be saved as .gcode, uploaded on a 
microSD card, and run on the Ender 3 syringe pumps. Or it can be sent using a computer connected to the USB.

G-code files can be easily shared between labs for improving reproducibility of experiments.

\section{Validation and Characterization}

Pumps using designs for translating rotational motion to linear motion using a lead screw, are affected by the quality of the motors/drivers and by the structural stability of the apparatus. The motors and drivers used here have been used in 3D printing since many years, and usually a failed 3D print can be traced back to a failure in the hot-end or the extruder, and only rarely to the XYZ motion of the printer.

The linear rail and the bearings system are also directly translated from the $3 \mathrm{D}$ printing motion to the syringe pump motion. And in this case, if the wheel pressure is properly calibrated to the extruded aluminum frame, there are no possible failures.

As shown in the build instruction, we screw all the 3D printed parts on the frame and checked that there was no loose movement.

With this set-up we managed to reproducibly deliver $10 \mu \mathrm{L}$ of water using a $1 \mathrm{~mL}$ syringe pump. We repeated the command 10 times, using an analytical balance to weight the delivered liquid. We measured an average of $10.4 \mathrm{mg}$ with an error of $+/-0.3 \mathrm{mg}$, which is indistinguishable from the error of the analytical balance used.

The amount of delivered liquid, as explained in the previous section, is dependent on the steps per $\mathrm{mL}$, and this can be finely tuned using an analytical balance and changing the values in the command M92.

Another important thing is not only the amount of liquid delivered, but the flow stability. This is especially interesting in microfluidics, where the flow at low speed, should be as stable as possible. We show how the flow from two or three pumps is stable in at low flow speed and in microfluidic devices. In Video S2, we used two $5 \mathrm{~mL}$ syringes for delivering $50 \mu \mathrm{L}$ at a speed of $5 \mu \mathrm{L} / \mathrm{min}$ in a PDMS/Glass microfluidic Y-channel $2 \mathrm{~mm}$ wide and with a height of $0.5 \mathrm{~mm}$. Even using such a large syringe, the laminar flow between the two flows is barely disturbed during the experiment.

Similarly, we used three $10 \mathrm{~mL}$ syringes for flowing $50 \mu \mathrm{L}$ at $25 \mu \mathrm{L} / \mathrm{min}$ in a three-way-in single PDMS microfluidic channel $1 \mathrm{~mm}$ wide and $0.25 \mathrm{~mm}$ height. Also in this case the three flows are barely disturbed at their interfaces.

We also succeeded in forming a multiphase system using the same three way in microfluidic device, where two inlets were used for flowing oil, and the central channel was used for the water phase (VideoS3). In this case, we used three syringe pumps delivering $50 \mu \mathrm{L}$ at a speed of 25 $\mu \mathrm{L} / \mathrm{min}$

\section{Acknowledgements}

We would like to thank Damien Leech for beta testing the pumps, and QuantERA (2017, project NanoSpin) for the financial support. 


\section{References:}

[1] W. Zeng, I. Jacobi, D.J. Beck, S. Li, H.A. Stone, Characterization of syringe-pump-driven induced pressure fluctuations in elastic microchannels, Lab. Chip. 15 (2015) 1110-1115. https://doi.org/10.1039/C4LC01347F.

[2] F. Zhao, D. Cambié, V. Hessel, M.G. Debije, T. Noël, Real-time reaction control for solar production of chemicals under fluctuating irradiance, Green Chem. 20 (2018) 2459-2464. https://doi.org/10.1039/C8GC00613J.

[3] N. Convery, N. Gadegaard, 30 years of microfluidics, Micro Nano Eng. 2 (2019) 76-91. https://doi.org/10.1016/j.mne.2019.01.003.

[4] J.M. Pearce, N.C. Anzalone, C.L. Heldt, Open-Source Wax RepRap 3-D Printer for Rapid Prototyping Paper-Based Microfluidics, J. Lab. Autom. 21 (2016) 510-516. https://doi.org/10.1177/2211068215624408.

[5] R. Khnouf, D. Karasneh, E. Abdulhay, A. Abdelhay, W. Sheng, Z.H. Fan, Microfluidicsbased device for the measurement of blood viscosity and its modeling based on shear rate, temperature, and heparin concentration, Biomed. Microdevices. 21 (2019) 80. https://doi.org/10.1007/s10544-019-0426-5.

[6] B. Wijnen, E.J. Hunt, G.C. Anzalone, J.M. Pearce, Open-Source Syringe Pump Library, PLOS ONE. 9 (2014) e107216. https://doi.org/10.1371/journal.pone.0107216.

[7] J.M. Pearce, Return on investment for open source scientific hardware development, Sci. Public Policy. 43 (2016) 192-195. https://doi.org/10.1093/scipol/scv034.

[8] M. Coakley, D.E. Hurt, 3D Printing in the Laboratory: Maximize Time and Funds with Customized and Open-Source Labware, J. Lab. Autom. 21 (2016) 489-495. https://doi.org/10.1177/2211068216649578.

[9] A.S. Booeshaghi, E. da V. Beltrame, D. Bannon, J. Gehring, L. Pachter, Principles of open source bioinstrumentation applied to the poseidon syringe pump system, Sci. Rep. 9 (2019) 12385. https://doi.org/10.1038/s41598-019-48815-9.

[10] R.J. LeSuer, K.L. Osgood, K.E. Stelnicki, J.L. Mendez, OMIS: The Open Millifluidic Inquiry System for small scale chemical synthesis and analysis, HardwareX. 4 (2018) e00038. https://doi.org/10.1016/j.ohx.2018.e00038.

[11] V.E. Garcia, J. Liu, J.L. DeRisi, Low-cost touchscreen driven programmable dual syringe pump for life science applications, HardwareX. 4 (2018) e00027. https://doi.org/10.1016/j.ohx.2018.e00027.

[12] P. Almada, P.M. Pereira, S. Culley, G. Caillol, F. Boroni-Rueda, C.L. Dix, G. Charras, B. Baum, R.F. Laine, C. Leterrier, R. Henriques, Automating multimodal microscopy with NanoJ-Fluidics, Nat. Commun. 10 (2019) 1223. https://doi.org/10.1038/s41467-019-092319.

[13] A.S. Samokhin, Syringe Pump Created using 3D Printing Technology and Arduino Platform, J. Anal. Chem. 75 (2020) 416-421. https://doi.org/10.1134/S1061934820030156.

[14] J.Z. Milanovic, P. Milanovic, R. Kragic, M. Kostic, "Do-It-Yourself” reliable pH-stat device by using open-source software, inexpensive hardware and available laboratory equipment, PLOS ONE. 13 (2018) e0193744. https://doi.org/10.1371/journal.pone.0193744.

[15] J.R. Lake, K.C. Heyde, W.C. Ruder, Low-cost feedback-controlled syringe pressure pumps for microfluidics applications, PLOS ONE. 12 (2017) e0175089. https://doi.org/10.1371/journal.pone.0175089. 
[16] M.S. Cubberley, W.A. Hess, An Inexpensive Programmable Dual-Syringe Pump for the Chemistry Laboratory, J. Chem. Educ. 94 (2017) 72-74. https://doi.org/10.1021/acs.jchemed.6b00598.

[17] T. Kassis, P.M. Perez, C.J.W. Yang, L.R. Soenksen, D.L. Trumper, L.G. Griffith, PiFlow: A biocompatible low-cost programmable dynamic flow pumping system utilizing a Raspberry Pi Zero and commercial piezoelectric pumps, HardwareX. 4 (2018) e00034. https://doi.org/10.1016/j.ohx.2018.e00034.

[18] J.J. Davis, M. Padalino, A.S. Kaplitz, G. Murray, S.W. Foster, J. Maturano, J.P. Grinias, Utility of low-cost, miniaturized peristaltic and Venturi pumps in droplet microfluidics, Anal. Chim. Acta. 1151 (2021) 338230. https://doi.org/10.1016/j.aca.2021.338230.

[19] A. Gervasi, P. Cardol, P.E. Meyer, Open-hardware wireless controller and 3D-printed pumps for efficient liquid manipulation, HardwareX. 9 (2021) e00199. https://doi.org/10.1016/j.ohx.2021.e00199.

[20] A. Jönsson, A. Toppi, M. Dufva, The FAST Pump, a low-cost, easy to fabricate, SLA3D-printed peristaltic pump for multi-channel systems in any lab, HardwareX. 8 (2020) e00115. https://doi.org/10.1016/j.ohx.2020.e00115.

[21] H.N. Chan, Y. Shu, B. Xiong, Y. Chen, Y. Chen, Q. Tian, S.A. Michael, B. Shen, H. Wu, Simple, Cost-Effective 3D Printed Microfluidic Components for Disposable, Point-of-Care Colorimetric Analysis, ACS Sens. 1 (2016) 227-234. https://doi.org/10.1021/acssensors.5b00100.

[22] Y. Lee, B. Kim, I. Oh, S. Choi, Optofluidic Modular Blocks for On-Demand and OpenSource Prototyping of Microfluidic Systems, Small. 14 (2018) 1802769. https://doi.org/10.1002/smll.201802769.

[23] MarlinFirmware, Home, Marlin Firmware. (n.d.). https://marlinfw.org/ (accessed May 31, 2021).

[24] Ender-3 3D Printer, (n.d.). /goods-detail/ender-3-3d-printer (accessed May 31, 2021).

[25] G.O.T. Merces, C. Kennedy, B. Lenoci, E.G. Reynaud, N. Burke, M. Pickering, The incubot: A 3D printer-based microscope for long-term live cell imaging within a tissue culture incubator, HardwareX. 9 (2021) e00189. https://doi.org/10.1016/j.ohx.2021.e00189.

[26] S.C. 3D T.C. Ltd, Creality3DPrinting/Ender-3, 2021.

https://github.com/Creality3DPrinting/Ender-3 (accessed June 1, 2021).

[27] Vsaggiomo/Ender3-syringe-pumps, GitHub. (n.d.).

https://github.com/Vsaggiomo/Ender3-syringe-pumps (accessed June 2, 2021).

[28] Printrun: Pure Python 3d printing host software, (n.d.). https://www.pronterface.com/ (accessed June 1, 2021).

[29] OctoPrint/OctoPrint, OctoPrint, 2021. https://github.com/OctoPrint/OctoPrint (accessed June 1, 2021). 